\title{
Disability in Mental illness : A Neglected issue
}

\author{
Subedi $\mathbf{S}^{1}$, Shyangwa $\mathbf{P M}^{2}$
}

1. Associate Professor, Department of Psychiatry, UCMS, Bhairahawa, Nepal. 2. Ex-Professor E Head, Department of Psychiatry, BPKIHS, Dharan, Nepal.

E-mail *Corresponding author : sandipsubedi@ hotmail.com

\section{BACKGROUND}

Mental health has been hidden behind a curtain of stigma and discrimination for too long. It is time to bring it out into the open. The magnitude, suffering and burden in terms of disability and costs for individuals, families and societies are staggering. In the last few years, the world has become more aware of this enormous burden and the potential for mental health gains. However, The disability related to mental illness has always been a neglected issue in the parlane of health.

Defining disability is not an easy task and it is becoming clear that no single definition can cover all aspects of disabilities. According to WHO, Disabilities is an umbrella term, covering impairments, activity limitations, and participation restrictions. An impairment is a problem in body function or structure; an activity limitation is a difficulty encountered by an individual in executing a task or action; while a participation restriction is a problem experienced by an individual in involvement in life situations. Thus, disability is a complex phenomenon, reflecting an interaction between features of a person's body and features of the society in which he or she lives.

In the past, mental illness have not received attention proportionate to the suffering they produce. The main reasons for this was that:

- Much of burden of disease is invisible to accounting,

- Mental illness do not produce large increase in mortality rate,

- Measuring costs in Quality Of Life and burden in family is difficult,

- Widespread misconception that psychiatric condition are not real illness,
- Perception that there are few or no effective treatment for mental illness.

In 1993 world development report estimated that mental health has world over produce $8.1 \%$ of Global Burden of Disease measured in Disability Adjusted Life Years (DALY) (toll greater than exacted by Tuberculosis, Cancer, Heart Disease). International Classification of Disease (ICD) and Diagnostic Statistical Manual (DSM) provided dramatic changes in approaches to psychiatric research over past two decades providing many informations regarding prevalence \& burden of psychiatric illnesses. Modern psychopharmacological agents have also provided effective treatment for much of the mental illness. These dramatic changes in psychiatry and psychiatric research paradigms provide an opportunity to re-evaluate the place of mental illness and their treatment in context of international health

Magnitude of Problem : Prevalence and global burden

The actual prevalence of disability in Nepal is difficult to precise. However, National census 2001, shows that about $0.45 \%$ of the total population are having disability. UNICEF's 2001 Situational Analysis of Disability in Nepal found that $1.63 \%$ of people were disabled. According to the World Health Organization, approximately 10 percent of the total world population are disabled. Thus it is presumed that at least 10 percent of Nepal's population suffers from disability. ${ }^{1}$

\section{Global burden of Mental Illness}

Neuro-psychiatric conditions are number one contributor to non-communicable disease burden worldwide. WHO has projected that by 
2030 AD, depression will be number one cause of disease burden in high income countries and will be one of the highest causes of disease burden in middle \& low income countries. ${ }^{2}$ Globally, depression will be responsible for a greater burden of disease than chronic lung disease, IHD, DM, CVA, Vision or hearing loss. ${ }^{3}$

Table 1: Estimated prevalence of mental illness, $\underline{2004^{2}}$

\begin{tabular}{|l|l|l|}
\hline Illness & World & South-east Asia \\
\hline $\begin{array}{l}\text { Unipolar } \\
\text { Depression }\end{array}$ & $\begin{array}{l}151.2 \\
\text { millions }\end{array}$ & 40.9 millions \\
\hline BPAD & 29.5 & 7.2 \\
\hline F20 & 26.3 & 6.2 \\
\hline Epilepsy & 40.0 & 9.8 \\
\hline $\begin{array}{l}\text { Alcoholuse } \\
\text { disorder }\end{array}$ & 125.0 & 21.5 \\
\hline Parkinson disease & 5.2 & 0.7 \\
\hline $\begin{array}{l}\text { Alzheimer and } \\
\text { other dementia }\end{array}$ & 24.2 & 2.8 \\
\hline Migraine & 324.1 & 70.3 \\
\hline
\end{tabular}

Nepal, family member of mentally ill has to spend around NRS 25,000 per year as service cost. The indirect cost is not evaluated. ${ }^{5}$

\section{Why are Mental illness are more disabling?}

Disability associated with mental disorders rank among the most widespread and severe public health problems and the prevalence of disability associated with mental disorder is expected to grow as a result of variety of factors, including increased life expectancy and the success of new treatments that reduced fatality rates and control acute symptoms, but donot always prevent chronic mental impairment. ${ }^{7}$

The irregular nature of mental illness may create problems in establishing or maintaining consistent work or school patterns. The irregular nature of mental illness might also impair an individual's performance.

Many individuals do not disclose an illness for fear of stigma and discrimination. This fear may be compounded if an employee feels that a job is in jeopardy or a student worries that admission

Psychiatric disorders are one of the most common and prevalent illnesses that widely affect world population accounting for nearly 31 percent of world's disability. Five of the 10 leading causes of disability worldwide fall in the category of mental disorders: major depression, alcohol use, bipolar affective disorder, schizophrenia and obsessivecompulsive disorder. ${ }^{4}$ Mental disorders comprise 4 of the top 5 sources of premature death and disability in 15-44 yrs in the west. Estimates of costs are not available for all the various disorders, and certainly not for all the countries in the world. Most

Table 2: The overall economic burden of mental disorder 6

\begin{tabular}{|c|c|c|c|}
\hline & Care costs & $\begin{array}{l}\text { Productivity } \\
\text { Costs }\end{array}$ & Other costs \\
\hline Sufferer & $\begin{array}{l}\text { Treatmend and } \\
\text { service } \\
\text { fees/payment }\end{array}$ & $\begin{array}{l}\text { Work } \\
\text { disability; lost } \\
\text { earnings }\end{array}$ & \begin{tabular}{lr}
\multicolumn{2}{l}{ Anguish/sufferi } \\
ng; & treatment \\
side & effects; \\
siucide &
\end{tabular} \\
\hline $\begin{array}{l}\text { Family } \\
\text { and } \\
\text { friends }\end{array}$ & $\begin{array}{l}\text { Informal care } \\
\text { giving }\end{array}$ & Time off work & $\begin{array}{l}\text { Anguish; isolation; } \\
\text { stigma }\end{array}$ \\
\hline Employers & $\begin{array}{l}\text { Contribution to } \\
\text { treatment and care }\end{array}$ & $\begin{array}{l}\text { Reduced } \\
\text { productivity }\end{array}$ & - \\
\hline Society & $\begin{array}{lr}\text { Provision } & \text { of } \\
\text { mental health care } \\
\text { and } & \text { general } \\
\text { medical } & \text { care } \\
\text { (taxation } & / \\
\text { insurance) } & \end{array}$ & $\begin{array}{l}\text { Reduced } \\
\text { productivity }\end{array}$ & $\begin{array}{l}\text { Loss of lives; } \\
\text { untreated illnesses } \\
\text { (unmet needs); } \\
\text { social exclusion }\end{array}$ \\
\hline
\end{tabular}

methodologically sound studies

have been conducted in the United States and the United Kingdom. At 1990 prices, mental health problems accounted for about $2.5 \%$ of GNP in the United States.

Social burden is all the resources lost due to premature death or reduced productivity, hours spent by family members who otherwise could have been doing something productive. In may not be permitted. Anxiety often accompanies the effort to hide an illness and its symptoms.

Despite their effectiveness, for many people medications can also have side effects that create difficulties at work or in school.

Many people first develop symptoms of mental illnesses between the ages of 15 and 25 and traditional educational or vocational training 
may be delayed. This may affect their credentials for jobs or educational programs hence, their job opportunities.

The National Institute of Mental Health (NIMH) reports that $30 \%$ of adults with a mental illness also have had a diagnosable alcohol and/or drug abuse disorder during their lives. In addition, $53 \%$ of adults who have had substance abuse disorders have had one or more mental illnesses during their life times. Treatment and accommodation in these cases address both the effects of substance abuse as well as the effects of the person's mental illness. It has been demonstrated that in the patients with mood and anxiety disorders, residual disability and poor quality of life continue even after completion of symptom-linked treatment.8,9 There is amelioration of symptoms with pharmacotherapy, but social functioning and quality of life improve only with concerted efforts at rehabilitation that lasts for longer duration. ${ }^{10}$ Such facility is hardly available in many developing countries, and Nepal is not exception with regard to it. One in four people will develop a mental or behavioural disorder during their lifetime, ${ }^{11}$ however only approximately one third of these people will receive treatment. ${ }^{12}$ In some communities as little as $10.4 \%$ of people with a mental illness who are being treated will receive adequate treatment. ${ }^{12}$ This gap in care is most pronounced in low-income and middle-income countries, where fundamental resources are less accessible or unavailable.

In developing countries, the problem is even more acute because of lack of trained mental health workers, inadequate supplies of medication, inadequate information flow, and poor transport making health services impossible . In addition to this, developing countries contribute less than $1 \%$ of their total health expenditure to mental health thus adequate mental health services are not possible.

What can be the Consequences of Mental Illness??

Mental illness is associated with significant long term disability. Poor Mental Health significantly contributes to a cycle of poverty where people who experience social hardship and poverty are of increased risk of mental illness, and conversely those with mental illness are at increased risk of poverty. ${ }^{13}$

Having a mental illness can place an individual at having higher risk for developing other illness eg, depression is noted an independent risk factor for stroke, prevalence of diabetes in patient with F20 is at least five times that of general population.

Mental illness is also a risk factor for accidental and non-accidental injury. Conversely, having a physical illness can place an individual at high risk for developing mental illness(14). Disability itself is a risk factor for developing depression. It may be due to disease process directly affecting the brain or commonly due to psychological strain.

Mental illness may also contribute to disease burden through higher risk exposure. For example, mood disorders and schizophrenia are strongly associated with obesity and tobacco smoking, both of which are recognised as independent risk factors for heart disease ${ }^{14}$

Maternal mental illness also affects child health and may increase infant mortality ( mothers who are experiencing psychoses during pregnancy are twice as likely to have babies that are stillborn). ${ }^{14}$ Maternal mental illness such as depression may adversely affect bonding between mother and child, and may result in a child's failure to thrive.

Importantly, mental illness may also increase communicable disease transmission such as HIV/AIDS, malaria and tuberculosis, ${ }^{14}$ the leading causes of disease burden in low-income countries.

Mental illness may also result in poor physical health outcomes through delayed diagnosis, decreased access to care and decreased compliance with care.

\section{Attempts to Overcome Disability in NEPAL}

Various government and private hospitals in the country are providing Psychiatric care. In the recent years, the number of total beds available for the inpatient treatment of mentally ill has drastically increased with the increasing number of private medical colleges in the country. This is an important attempt to reduce disability in the country. Various NGO's, INGO's are working in the field of mental illness which has also added some help to the government's 
attempt to reduce disability. Many De-addiction centres established in the country are providing services to the people with substance use problems thus attempting to reduce disability. Job opportunities by various private organizations to the people with disability is an important attempt made by the organizations to reduce disability. National sports are regularly organized to persons with special ability. This is an attempt to help them reveal their talent in the field. It also attempts to reduce disability. Inclusion of disabled people in the constitution assembly is an important attempt to reduce the disability. It provides an opportunity to disabled people to fight for their rights. Disability policy in interim constitution has attempted to safeguard and promote the rights and interests of persons with disability. A number of Laws and policies have provisions related with the people with mental health and physical disability. The policy includes state policy on education, training, health, employment, concession and facilities; sports and recreation; fund for disables, disables home, legal support and public awareness regarding the persons with disability. Similarly, the government increased the amount of allowances being provided to people with disability and has emphasized for the implementation of programs for rehabilitating and generating opportunities of career development for the disabled. In Nepal, since 1992, every year December 3rd is celebrated as International Day of the Disabled persons with various programmes like procession of disabled persons, talk programmes, workshops, seminars etc.

\section{CONCLUSION}

Today some 400 million people suffer from mental and brain disorders. Schizophrenia, alcohol use, bipolar and obsessive compulsive disorders are among the diseases responsible for the highest disability ratings in the world. Moreover, these numbers are expected to rise sharply over the next few decades, particularly among people in the developing world. Yet, despite the enormous social and economic burdens posed by mental health problems, more than $40 \%$ of the world's countries have no articulated mental health policy, and over 30\% have no mental health programmes. A global strategy to address the mental health crisis is needed, one which will incorporate both prevention and care. It should be able to provide the much-needed services, treatment and support to a larger proportion of people suffering from mental disorders than they receive at present: services that are more effective and more humane; treatments that help them avoid chronic disability and premature death; and support that gives them a life that is healthier and richer - a life lived with dignity. We can also expect greater financial returns from increased productivity and lower net costs of illness and care, apart from savings in other sector outlays.

References:

1.Joshi SK. Disability in Nepal: Kathmandu University Medical Journal 2004;2 (1): 1-5.

2.The Global Burden of disease, 2004 update, WHO.

3.Mathers C.D., Loncar D. (2006). Projections of Global Mortality and Burden of Disease from 2002 to 2030. PLoS Med, 3(11): e442. DOI 10: 1371/journal.pmed.0030442

4.The World Health Report 2001: Mental health: new understanding, new hope. Geneva: World Health Organization; 2001.

5.Mental Health Atlas, 2005-WHO, Nepal.

6.Investing in Mental Health, WHO, 2003.

7.Initiative of support to people disabled by mental illness, WHO.

8.Bystritsky A, Saxena S, Maindment K, Vapink T, Tarlow G, Rosen R. Quality of life changes among patient with obsessive- compulsive disorder in a partial hospitalization program. Psychiatr Serv 1999; 50 : 412-4.

9.Hollander E, Kwon JH, Stein DJ, Broatch J, Rowland CT, Himelein CA. Obsessive compulsive disorder: Overview and quality of life issues. J Clin Psychiatry 1996; 57 (Suppl 8): 3-6.

10. Lehman AF. Measures of quality of life among persons with severe and persistent mental disorders. Soc Psychiatry Psychiatr Epidemiol 1996; 31 : 78-88.

11. The bare facts. Geneva, World Health Organisation, 2008. (url:http://www.who.int) mental_health/en, accessed 02/04/08).

12. Chisholm, D., Flisher, A.J., Lund, C., Patel, V., Saxena, S., Thornicroft, G., Tomlinson, M. (2007). Scale Up Services For Mental Disorders: A Call For Action, Lancet, 370: 1241-52.

13. Breaking the vicious cycle between mental illhealth and poverty. Geneva, World Health Organization, 2007 (url: wwww.who.int/mental_health/policy/ development/en/index.html, accessed 04 September 2007; Mental Health Core to Development Information Sheet, Sheet1).

14. Prince, M., Patel, V., Saxena, S., Maj, M., Maselko, J., Phillips, M., Rahman, A. (2007). No Health Without Mental Health, The Lancet, DOI 10:1016/S01406736(07)61238-0 